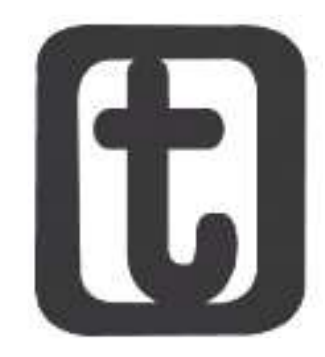

\title{
TEORIA DAS PROFISSÕES, MARXISMO E SERVIÇO SOCIAL
}

\author{
Theory of professions, marxism and social work
}

\section{Ludson Rocha Martins*}

\section{RESUMO}

O presente texto elabora subsídios, a partir do debate brasileiro sobre o Serviço Social, para uma análise marxista das ocupações especializadas. Teoricamente, são tratadas algumas das bases da sociologia das profissões, bem como o pensamento de Vicente Faleiros, Marilda lamamoto e José Paulo Netto sobre atuação do assistente social. Por fim, esboça-se a partir de tais nomes alguns apontamentos sobre a natureza das profissões na sociedade moderna.

\section{PALAVRAS CHAVE}

Marxismo. Sociologia das profissões. Serviço Social.

\section{ABSTRACT}

The present paper elaborates subsidies, to from the Brazilian debate on the Social Work, for a marxist analysis of the specialized occupations. Theoretically, some of the bases of the sociology of the professions are dealt with, as well as the thought of Vicente Faleiros, Marilda lamamoto and José Paulo Netto over the social worker. Finishing, from these names, some notes on the nature of professions in modern society are outlined.

\section{KEYWORDS}

Marxism. Sociology of the professions. Social Work.

\section{INTRODUÇÃO}

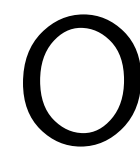

problema da especificidade das profissões é lateral ao debate marxista (MARTINS, 2014a; DURAND, 1975). Este - ainda que preocupado com a temática do labor, dos processos de produção e reprodução social -, pouco tratou da natureza e da conformação das especializações do trabalho, procurando explicitar em termos categoriais as suas determinidades.

\footnotetext{
* Assistente Social. Mestre em Serviço Social. Assistente social da Prefeitura Municipal de Nova Lima (PMNL, Nova Lima, Brasil). Praça Bernardino de Lima, n 80, Centro, Nova Lima (MG), CEP.: 34000-970. ORC ID: https://orcid.org/oooo-0002-7484-8341. E-mail: <ludson@outlook.com>.
}

\section{DOI 10.22422/temporalis.2019v19n37p45-64} material em qualquer suporte ou formato, bem como adaptar, transformar e criar a partir deste material para qualquer fim, mesmo que comercial. O licenciante não pode revogar estes direitos desde que você respeite os termos da licença.

Temporalis, Brasília (DF), ano 19, n. 37, p. 45-64, jan./jun. 2019. | ISSN 2238-1856 


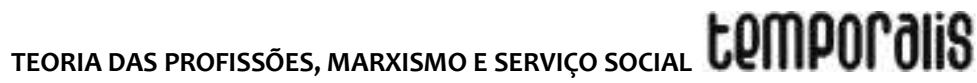

Em sua particularidade as ocupações profissionalizadas são alvo das ciências sociais, a partir de um conjunto de análises típicas da tradição anglo-saxã, que se desenvolveram desde o início do século XX, agrupadas num campo extenso e diverso, conhecido como sociologia das profissões.

Contudo, em que pese a força das elaborações de língua inglesa, em termos genéticos, a origem de tal área remonta às considerações de Dürkheim (2007) no Prefácio à segunda edição Da divisão do trabalho social, no qual o autor elabora a temática da corporação, vista como instância estabilizadora do sistema social.

Absorvendo essa posição originária, o debate funcionalista, com base em nomes como Carr-Saunders e Wilson, Parsons, além de Merton (ALMEIDA, 2010), enfocou as profissões como instâncias de reprodução social, cujos traços partiriam de duas determinações irradiadoras: o saber acadêmico e a especialização laborativa. Nesta visão, o fenômeno profissional seria uma forma de solidariedade, processo de regulação da moderna divisão do trabalho, bem como de produção e fixação de identidades. Seria o meio ideal de realização da utopia conservadora - "[...] modernização e continuidade, interdependência social e individualização" (MARTINS, 2014a, p. 42).

Através destas contribuições o estudo das ocupações laborais se desenvolveu, ganhando ao longo do tempo direções teórico-metodológicas variadas. Estas se estendem desde o interacionismo simbólico, até às discussões weberianas e pós-estruturalistas.

Neste contexto, o afastamento do marxismo pode ser explicado pelo fato de que a própria sociologia das profissões nasce e ganha corpo como uma abordagem a ele oposta no campo dos estudos sobre o trabalho (MARTINS, 2014b). Nela, ao invés de uma visão de totalidade que busca dissecar os elementos fundamentais do labor e de suas particularizações, temos uma abordagem que procura tematizar o assunto para além das oposições entre capital e trabalho (ressaltando a importância dos extratos sociais médios); no lugar da produção e das classes, a problematização do estatuto cultural e simbólico das ocupações; ao invés da eficácia inerente à atuação laboral, a legitimidade pelo status, sobretudo em sua acepção jurídico-política, como forma de compreender a afirmação das categorias profissionais.

Assim, o distanciamento entre as perspectivas está assentado não apenas nas suas diferentes orientações e ênfases, mas também na estrutura lógica dos padrões de cientificidade que as colimam. Isto é, enquanto a teoria das profissões se conforma por meio de um conjunto de coordenadas heurísticas esquematizadas (de ordem dialógica ou instrumental), ou seja, através de um modelo conceitual, visto como um ferramental de análise para expor leis, discursos ou relações significativas, o marxismo tem como alvo a verdade científica (tida como um dos meios de mudança do real), voltando-se a problemática do ser e as coisas da efetividade.

Contudo, isto não significa a inexistência de interlocução entre os campos. Oppenheimer (1972) em The proletarianization of the professional, elaborou, sob inspiração da tradição marxista, a visão segundo a qual "[...] os trabalhadores de colarinho branco agora estão 
sendo substituídos por um tipo de trabalhador profissional autônomo na camada superior do emprego técnico-profissional"1 (OPPENHEIMER, 1972, p. 213, tradução nossa).

Por tal visão, haveria uma tendência de erosão das estruturas identificadas com o tipo ideal de profissão, que remete a um conjunto restrito de ocupações com trabalhadores organizados e formação superior, agentes que seriam beneficiados por uma legislação que delimita e orienta seu ofício, bem como por associações destinadas a certificação e a fiscalização da intervenção ocupacional.

A proletarização dos profissionais seria o resultado do avanço tecnológico dos países desenvolvidos, que populariza os saberes monopolizados por pequenos grupos e impõe a rotinização do trabalho especializado, fragilizando a condição das ocupações, inclusive por meio da insegurança empregatícia e rebaixamento salarial (OPPENHEIMER, 1972).

Como mostra Meneghetti (2009), outra abordagem similar é a de Braverman (1987), cujos argumentos, de certa forma, se dirigem aos mesmos problemas. Para ele, a racionalização do trabalho e a burocratização das ocupações científicas e de gerência aponta para a disseminação de intervenções alienantes entre os profissionais. Elementos como uma rigorosa divisão do trabalho (com a estratificação de agentes de uma mesma ocupação divididos em subáreas), parcelamento das atividades laborais, com a perda (relativa ou total) do controle sob o trabalho, e o fim do monopólio do conhecimento ocupacional marcariam o universo atual das profissões. Surgiria, assim, um contingente com meios de vida e de trabalho cada vez mais próximos aos do antigo operariado.

Tais formulações, no entanto, partem dos pressupostos construídos pela sociologia das profissões. Toda análise - em que pese sua inspiração marxista - toma como fato o conceito de profissão, tal como desenvolvido pelo funcionalismo, pelas correntes weberianas ou interacionistas, não questionando explicitamente a raiz heurística que subscreve tais ideias (MARTINS, 2014a; 2014b).

Ou seja, não é possível identificar, de forma clara, uma elaboração categorial do marxismo em relação ao fenômeno das profissões. O que existe são investigações sobre o mundo do trabalho, e, dentro delas, a avaliação da questão das ocupações em sua forma concreta, não se colocando o profissionalismo como uma categoria típica do modo de produção capitalista, dotada de traços básicos, ao mesmo tempo que de expressões históricas variadas (MARTINS, 2014a; ALMEIDA, 2010; DURAND, 1975).

Daí que um possível desenvolvimento marxista da temática tenha de partir desse universo de pesquisas sobre as ocupações particulares. Nos últimos anos, inclusive, foi erigida uma extensa bibliografia discutindo áreas como a Medicina (NAVARRO, 1976), Direito (CARVALHO, 1992), Pedagogia (APPLE, 1995; SAVIANI, 2003), ou atores como gerentes e trabalhadores de escritório (WRIGHT, 1976; EDGELL, 1993). Nesse âmbito, se destacam as abordagens dedicadas ao Serviço Social, desde o Radical Social Work britânico e norteamericano (FERGUSON, 2011; CORRIGAN; LEONARD, 1978) às interlocuções críticas do service social em língua francesa (VERDĖS-LEROUX, 1986), e, principalmente, o Serviço

\footnotetext{
${ }^{1}$ Ou como dito no original: "[...] a white-collar proletarian type of worker is replacing the autonomous professional type of worker in the upper strata of professional-technical employment (OPPENHEIMER, 1972, p. 213).
} 
Social Latino-Americano. Neste último, a partir do chamado Movimento de Reconceituação e do processo de Renovação no Brasil, o marxismo passou a ocupar um lugar central, tanto na interpretação da história profissional, quanto no que toca as perspectivas que balizam a construção de estratégias de intervenção (IAMAMOTO, 2008; MONTAÑO, 2011).

Na América Latina, além da rearticulação política do Serviço Social, diversos artigos, teses, dissertações e livros foram publicados constituindo um profundo acúmulo teórico. De fato, pode-se falar (ainda que de forma imprecisa) numa das mais extensas literaturas de extração marxista sobre a análise concreta das profissões - sobretudo quando tratamos do Serviço Social Brasileiro - no qual o marxismo possui a mais nítida proeminência (MARTINS, 2014a; PAYNE, 2002; MONTAÑO, 2011).

A hipótese, neste sentido, é que seria possível extrair das discussões sobre o Serviço Social no país contribuições relevantes para a elaboração de uma teoria marxista das profissões (MARTINS, 2014a; 2014b). Mais especificamente, almeja-se identificar no pensamento de Vicente Faleiros, Marilda lamamoto e José Paulo Netto, os três maiores nomes da categoria no Brasil, aspectos fundamentais do fenômeno profissional.

Para alcançar este objetivo será abordado, de forma sucinta, o universo da teoria das profissões, de maneira a condensar algumas de suas linhas básicas. Em seguida a análise se concentrará na questão da elaboração categorial no marxismo (avaliando a viabilidade de tal perspectiva na esfera das ocupações especializadas). Finalizando, serão abordados os autores em apreço, buscando-se neles possíveis indicações para a compreensão do problema destacado.

\section{A TEORIA DAS PROFISSÕES}

A que perguntas a sociologia das profissões responde? O que caracteriza esse campo de discussão? Qual o seu objeto? O estudo das profissões surge quando o mercado de trabalho moderno passa a ser influenciado por (novas) especialidades, cujos rendimentos e papel social destoam tanto dos antigos artesãos, quanto do operariado que emerge no século XIX.

Contrariamente ao proletariado tradicional, agentes como médicos, engenheiros e advogados desempenhariam atividades não braçais (de natureza intelectual e não repetitiva), teriam honorários relativamente elevados, autonomia na realização de suas tarefas e status considerável. Diferentemente dos ofícios, a reprodução profissional não estaria baseada na relação mestre-aprendiz, mas na formação universitária, calcada em uma ética codificada e em conceitos e ideias abstratos (DUBAR, 2012; MENEGHETTI, 2009).

Nas palavras de Dubar (2012):

[...] essas atividades que possibilitam uma identificação positiva são, ao mesmo tempo, escolhidas (ou, pelo menos, entendidas como tal), autônomas (isto é, vividas desse modo) e abertas para carreiras (no sentido de uma progressão ao longo da vida). Essas atividades de trabalho, qualificadas de profissionais, são produtoras de obras, quer se trate de arte, artesanato, ciências ou outras atividades criadoras de algo de si, ou produtoras de serviços úteis a outro 
(médicos, jurídicos, educativos). Elas dão um sentido à existência individual e organizam a vida de coletivos. [...] não se reduzem à troca econômica de um gasto de energia por um salário, mas possuem uma dimensão simbólica em termos de realização de si e de reconhecimento social [...] (DUBAR, 2012, p. 353-354).

Das três visões que galvanizam a sociologia das profissões, o funcionalismo é a que se apresenta como tradicional. Tal corrente aborda o profissionalismo em termos estáticos: identificados os elementos invariáveis da profissionalização, ter-se-ia uma forma moderna de socialização e coesão social, uma comunidade sem base geográfica, fundada numa solidariedade de interesses (GOOD, 1957 apud MENEGHETTI, 2009).

Ao abordar a Medicina, Parsons (1982) assinala que o processo de constituição das profissões é a maneira pela qual uma ocupação adquire uma condição jurídica particularizada - marcada por uma institucionalidade dedicada a sua proteção credencial. Este status específico seria atingido quando cumpridas três exigências básicas: I) a especialização de saber; II) o desprendimento afetivo e, III) a especialização funcional. Sem estes pontos não existiria profissão, uma vez que as ocupações simples não seriam instituições cristalizadas, mas sistemas de práticas dotados de alguma perenidade.

Ou seja, seriam profissionais aquelas estruturas que dominam um conjunto particular de saberes e ações certificados e reconhecidos pelo Estado; que tem sua reprodução fundada no ensino acadêmico (que forneceria um treinamento prolongado, responsável por uma forma sui generis de socialização) e cujos agentes se relacionam com seus clientes a partir uma promessa de confiabilidade sustentada por uma vocação.

Também num ângulo funcionalista, Merton (1970; 1982), ampliando as ideias de Parsons, ressalta a negatividade das funções dos coletivos ocupacionais. A especialização funcional e a missão de serviço esconderiam o fato de os profissionais serem agentes típicos da burocracia - intelectuais eficientes e racionais, porém dependentes e que se refugiam no segredo, sendo suscetíveis a incapacidade treinada - o problema da utilização inconsequente de métodos consagrados, mas obsoletos para o trabalho.

Criticando o modelo funcionalista, o interacionismo simbólico propõe outra interpretação das ocupações especializadas. Nele a análise dinâmica do problema sugere o estudo das profissões como processo, uma articulação constante de práticas, identidades e instituições no âmbito da divisão do trabalho.

Em Men and their work Hughes (1958) coloca em pauta a ideia de licença, segundo o qual a profissionalização designa um movimento em que uma ocupação - independente da sua origem ou práticas - adquire e sustenta a habilitação normativa para o exercício de uma função laboral, ou seja, tornar-se profissional não consistiria somente na obtenção de status, mas na capacidade de mantê-lo.

O fenômeno das profissões estaria associado às instâncias universitárias, que seriam não apenas responsáveis pela aprendizagem dos ofícios, mas instâncias de justificação pedagógico-jurídicas com poder delegado do Estado. Nesses termos, caberia às instituições de ensino a seleção e diplomação dos integrantes das ocupações, vinculando a estrutura profissional ao prestígio da ciência. 
Acima da autorização acadêmica, haveria o credenciamento corporativo, a forma máxima de legitimação dos profissionais, realizada pelas organizações dedicadas a proteção, promoção e celebração das ocupações (associações, conselhos de classe e etc.).

Somado a isso há o mandato - o substrato de relações sociais que assentaria o monopólio profissional.

[...] [este], segundo Hughes (1963), seria uma imagem social, o fundamento do prestígio de uma especialização como prática distinta e distintiva. Ele exprimiria, portanto, a sua capacidade de controlar certas atividades (ou interações) que se dirigissem ao enfrentamento de um problema social posto (MARTINS, 2014b, $\mathrm{p}$. 67).

A grande contribuição do interacionismo simbólico foi romper com a concepção funcionalista segundo a qual as profissões seriam formas homogêneas e superiores de trabalho, calcadas em processos controlados de socialização. Na perspectiva de Hughes (1958), posteriormente revisada e atualizada por nomes como Dubar, Becker, Strauss e etc., não há fronteiras rígidas entre as ocupações e profissões, mas dinâmicas em que diferentes tipos de trabalhadores se articulam na busca de valorização, proteção e desenvolvimento interpessoal (ALMEIDA, 2010). A própria ideia de um grupo laboral coeso, que compartilha um conjunto comum de práticas e valores seria pouco efetiva, posta a grande diversidade e conflitos no interior das profissões.

Desta forma,

[...] a socialização profissional, definida como a maneira pela qual [um sujeito] aprende seu trabalho e se conduz a vida ativa, não é exclusiva de algumas pessoas que exercem atividades de prestígio às quais se deve reservar o título de 'profissão', mas diz respeito a todos, do ponto mais alto ao mais baixo da escala social, do médico à auxiliar de enfermagem, do engenheiro ao operário, do professor universitário à professora auxiliar do ensino básico. Todos os 'trabalhos', mas também todos os 'trabalhadores' independentemente de gênero, cor ou religião, têm direito à qualificação de 'profissional'. Com a condição de que esses 'trabalhos' sejam organizados, definidos, reconhecidos como 'ofícios', isto é, atividades que requerem competências que possam ser certificadas (DUBAR, 2012, p. 364).

Mais recentemente a visão neoweberiana de Freidson $(1996 ; 1998)$ ganhou proeminência na discussão do estatuto das ocupações especializadas. Tal perspectiva vislumbra a dinâmica profissional como um movimento estruturado, marcado pela questão do poder. Nela, ser profissional é fazer parte de uma instituição que detém o controle de um nicho destacado da divisão do trabalho.

Isto é,

[...] a profissionalização é um processo pelo qual uma ocupação organizada, geralmente, mas nem sempre, por alegar uma competência esotérica especial e cuidar da qualidade de seu trabalho e de seus benefícios para a sociedade, obtém o direito exclusivo de realizar um determinado tipo de trabalho, controlar o treinamento para ele e o acesso a ele e controlar o direito de determinar e avaliar a maneira como o trabalho é realizado. [...] (FREIDSON, 1998, p. 98). 
Para Freidson (1996) as profissões concretizam o princípio ocupacional da organização do trabalho, através de uma reação à hegemonia das relações associativas racionais (as burocracias) como centro articulador da institucionalidade capitalista. Contudo, elas não seriam um contraponto ao fenômeno burocrático (cuja dinâmica homogeneíza as ocupações, combatendo a autonomia do funcionário), mas outra forma de estruturação do trabalho sob os seus próprios fundamentos.

Freidson (1998), alega que a estrutura de todo corpo profissional tende a se dividir em três partes com atributos específicos: a classe ocupacional, que reúne a maior parte dos agentes profissionais, que exercem as tarefas cotidianas no mercado; a classe administrativa, responsável pela relação da profissão com o Estado e pela defesa da atividade ocupacional (fiscalização, deontologia e etc.); e a classe cognitiva: que concentra as autoridades intelectuais que operam a produção de saber e o ensino da profissão, sendo responsável pela base formativa da sua reprodução social.

Sintetizando sua análise, o autor destaca seu tipo ideal de profissão, o qual apresenta as seguintes componentes:

- Uma ocupação que empregue um corpo especializado de conhecimentos e qualificações, e que seja desempenhada para a subsistência em um mercado de trabalho formal, gozando de status oficial e público relativamente alto e considerada não só de caráter criterioso, como fundamentada em conceitos e teorias abstratos.

- Jurisdição sobre um corpo especializado de conhecimentos e qualificações em uma divisão do trabalho específica, organizada e controlada pelas ocupações participantes.

- Controle ocupacional da prática desse corpo de conhecimentos e qualificações no mercado de trabalho (seja uma universidade ou uma empresa), por meio de uma reserva que exija que apenas os membros adequadamente credenciados possam executar as tarefas sobre as quais têm jurisdição e também supervisionar e avaliar seu desempenho. Estes últimos servem como a classe administrativa da profissão.

- A credencial utilizada para amparar sua reserva de mercado de trabalho é criada por um programa de treinamento que se desenrola fora do mercado de trabalho, em escolas associadas a universidades. O currículo de ensino é estabelecido, controlado e transmitido por membros da profissão que agem como corpo docente em tempo integral, atuando pouco ou nada no mercado de trabalho cotidiano. O corpo docente serve como classe cognitiva da profissão (FREIDSON, 1996, p. 152 - grifos do autor).

Importante dizer que as ideias de Freidson (1996; 1998) não incorrem nos mesmos problemas do funcionalismo, sendo, ao revés, uma perspectiva muito mais avançada. Nesse marco, as profissões seriam uma tentativa de grupos de trabalhadores, numa ordem racionalizada e burocratizada, para ampliar sua renda e retomar (ainda que de forma incompleta e instável) o domínio sobre suas ações, resultando numa comunidade de identificação estruturada (mesmo que cindida) para defesa e promoção de seus interesses e valores imediatos.

Necessário reter, de toda esta exposição, que a teoria das profissões se sustenta a partir de estudos sobre um conjunto de tipos de trabalho, focalizados em virtude de seu papel estruturador de formas de existência e ideação distintas do operário e do empresário tradicionais. O essencial seria notar que as estruturas legitimação profissional produzem padrões de socialização e reprodução ocupacional que complexificam o corpo social, sobretudo por criar disposições de ação e pensamento, bem como instituições econômicas típicas das chamadas classes médias. 
Por isso, inclusive, que o traço distintivo dessas especializações estaria situado na esfera do legítimo, uma vez que "[...] a essência da condição profissional designa um problema de status, que se projeta a partir das interações sociais e das identidades individuais para o campo jurídico" (MARTINS, 2014a, p. 68).

Diante desse cenário uma avaliação marxista ganha uma dimensão diferenciada. Ao avaliar as implicações concretas da profissionalização em termos econômico-políticos, o marxismo poderia acrescentar pontos decisivos a discussão, clarificando a inserção do fenômeno profissional na dinâmica mais ampla de produção e reprodução das relações sociais. Seria possível, assim, erigir uma problematização efetiva sobre o profissionalismo na contemporaneidade, tendo em vista a conformação atual do mundo do trabalho, entrelaçado às mudanças tecnológicas e a financeirização do capital.

\section{MARX E A ANÁLISE CATEGORIAL}

A obra de Marx não contempla um estudo explicitamente dedicado ao problema do método, porém, o caráter sistemático de sua estratégia investigativa pode ser recuperado junto a seus textos mais significativos, que têm sido revisitados inúmeras vezes e em várias direções com esta meta.

Não é objetivo do presente estudo dar conta de tal universo, apresentando uma resolução aprofundada sobre o assunto. A questão, no propósito de avançar no tratamento da teoria das profissões, é apenas reunir alguns apontamentos fundamentais sobre a descoberta das categorias no âmbito do projeto marxiano.

Isto é necessário, uma vez que a elaboração de um pensamento marxista sobre o fenômeno profissional exige um trabalho de rearticulação categorial, que permita a abordagem do problema neste padrão de cientificidade. Há que se considerar, nesse ângulo, que o pensamento marxista (como qualquer corrente científica) não é fechado e avesso ao conjunto do debate da teoria social (o que o tornaria um mero grupo sectário), contudo a abertura à descobertas e apontamentos exógenos não pode ser feita sem critério, sob o risco de comprometer tanto o pensamento incorporado como o sistema receptor (PAÇO CUNHA, 2012).

O processo de rearticulação categorial aparece, assim, como a devida caracterização de conceitos e descobertas exteriores no contexto da perspectiva marxista, que após situados e ressignificadas, adquirem coerência nesse campo teórico.

Antes de tudo, a perspectiva marxiana nega, principalmente a partir de A ideologia alemã, a visão que apreende a atividade teórica enquanto uma ação de natureza imparcial e contemplativa, dissociada do esforço prático de intervenção do homem sobre o mundo. Em Marx e Engels (2007) a teoria é instrumento de transformação da realidade, ainda que não seja o único, ou necessariamente o mais importante.

Neles a elaboração teórica parte do esforço humano de enfrentamento de problemas efetivos, que emergem a partir da existência social, em suas diversas dimensões. Daí, inclusive, que a teoria só tenha utilidade quando elucida os nexos que configuram os 
objetos sociais, isto é, quando é capaz de distinguir a essência da aparência, indicando a verdade profunda dos fatos, mesmo que de forma sempre provisória e incompleta.

Para Marx (2011), as descobertas da razão são explicitações do conteúdo dos próprios objetos do real (alvos do sujeito cognoscente), não devendo se constituir enquanto elaborações arbitrárias de tom unicamente subjetivo, o que diluiria sua eficácia. Os pressupostos marxianos almejam a efetividade: consistem na história dos homens que acumulam, através de um desenvolvimento social desigual, as experiências de outros que os antecederam. Tais sujeitos são dotados de liberdade e potencial limitado, mas que apresenta a capacidade de se ampliar e desenvolver.

Nesse sentido a história, o objeto central da teoria social, se estabelece por meio do trabalho enquanto complexo de atividades que garantem a produção e reprodução da vida humana. No ato laborativo os homens estabelecem relações junto ao mundo natural e a seus pares, criando e recriando suas próprias necessidades.

O desenvolvimento do trabalho ampliou às forças produtivas nas sociedades primitivas, permitindo a existência de excedentes, condição para o desenvolvimento de desigualdades (por meio da apropriação da riqueza coletiva), mas também para o surgimento das mais diferentes formas de prática social (a arte, ciência, a religião, a função social de direção, etc.), possibilitadas pela ampliação do tempo disponível aos sujeitos para além do trabalho e pelos fundamentos deste enquanto protoforma, modelo para atividades sociais mais complexas.

Daí que o modo de ser dos indivíduos e da sociedade seja determinado não pelas suas representações (isoladamente tomadas), mas por sua existência, isto é, pelos mecanismos e relações que ordenam a vida. Por isso, em Marx (2011) a maneira como os homens se organizam para produzir se mostra a grande chave que permite a classificação e elucidação dos tempos históricos.

Marx parte, portanto, da objetividade como um dado, quer dizer, da existência por si da efetividade, bem como da possibilidade de esta ser conhecida e reproduzida mentalmente, de haver apreensão ideal das formas determinantes da concretude, de se fazer ciência e alcançar a verdade (ASSUNÇÃO, 2013, p. 47).

Ademais, a grande diferença de Marx (2011) é ter o objeto (e não o sujeito) como centro. Isso representou uma recusa a visão hoje predominante que estipula que a pesquisa é uma dinâmica regida por regras e conceitos subjetivamente determinados e exteriores ao real, cuja a construção é delineada previamente em passos e processos que precisam ser aplicados pelo investigador de forma meticulosa.

O legado de marxiano não comporta um encaminhamento a priori das formas de se interpelar o real, estas devem ser formuladas no concurso da análise, que busca reconstituir no intelecto os aspectos decisivos, as permanências e as tendências de transformação dos fenômenos sociais.

Isto é,

[...] em Marx não há tratamento autônomo da questão do método, a qual aparece sempre articulada ao ente, relação ou processo a ser estudado. Particularmente, só é discutida no bojo do próprio procedimento de análise das coisas e

Temporalis, Brasília (DF), ano 19, n. 37, p. 45-64, jan./jun. 2019. ISSN 2238-1856 
subordinada à efetividade. Não há nenhuma garantia preliminar de acesso à verdade, mas esta é encontrada apenas por meio de uma escavação, de uma descoberta, de um exame acurado das especificidades da coisa estudada no tocante a sua configuração interna e à inter-relacional - que capte e reproduza, afinal, 'a lógica da coisa', que apreenda 'a lógica específica do objeto específico' (MARX, 2005, p. 108) [...] cujas mediações, proposições e especificações dá a conhecer segundo as características que lhes são imanentes (ASSUNÇÃO, 2013, p. 47).

Como demonstrou Chasin (1995), ao identificar este aspecto definidor do pensamento marxiano ${ }^{2}$, tal análise se realiza a partir de abstrações, ou seja, da mentalização de traços dos fenômenos capazes de reconstituir suas leis tendenciais, e que são enunciados sob a forma de categorias.

Uma abstração adequada toma corpo quando a confrontação entre o real e o pensamento permite absorver e isolar "[...] das estruturas humanas existentes, fatores e elementos que permitem a sua caracterização, porquanto vetores gerais das suas dinâmicas fundantes e determinantes" (MARTINS, 2014a, p. 22).

A razoabilidade de uma abstração se manifesta, pois, quando retém e destaca aspectos reais, comuns às formas temporais de entificação dos complexos fenomênicos considerados. A razoabilidade está no registro ou constatação adequados, 'através da comparação', do que pertence a todos ou a muitos sob diversos modos de existência (CHASIN, p. 1995, 422).

Na Introdução de 1857, um dos raros momentos em que Marx (2011) discute mais detidamente as questões do método, aparecem considerações relevantes sobre capacidade das categorias para destacar dos objetos sociais aspectos de caráter geral particular, isto é, "[...] concreto e simples, mas também abstrato e determinado" (PAÇO CUNHA, 2012, p. 177).

Ao tratar da noção de produção em geral na economia burguesa (por meio da qual procurava-se indicar os fatores indispensáveis para toda e qualquer produção - terra, capital e trabalho), Marx (2011) criticou a arbitrariedade da elaboração dos conceitos, que projetavam sobre o conjunto da história humana os traços e elementos da produção econômica moderna.

Segundo ele, ao se deparar com a necessidade de explicação do modo de produção capitalista, a economia política clássica, ela mesma um produto das relações sociais que engendraram a burguesia como classe dominante, naturalizou as relações sociais que lhe eram contemporâneas, considerando-as como relações sempre existentes, comuns a qualquer formação social.

Neste sentido, o contra-argumento marxiano é simples e preciso: como o capital e trabalho (assalariado) poderiam ser determinantes das sociedades antigas se tais relações eram a elas estranhas, isto é, inexistentes nessas estruturas? Ou seja, como falar em capital

\footnotetext{
${ }^{2} \mathrm{E}$ que no debate chasiniano ficou conhecido como teoria das abstrações, ou seja, um conjunto estratégico de ponderações que explicitariam o modo propriamente marxiano de interpelar o real. Para um aprofundamento sugere-se a leitura de Marx - estatuto ontológico e resolução metodológica, texto publicado pelo autor em 1995.
}

Temporalis, Brasília (DF), ano 19, n. 37, p. 45-64, jan./jun. 2019. ISSN 2238-1856 
(financeiro, industrial, mercantil), sem o seu moderno processo de valorização? Como abordar os sistemas de produção antigos, tendo como parâmetro a noção (capitalista) de propriedade? Qualquer proposta com estas características seria insuficiente, comportando equívocos que a tornaria incapaz de vislumbrar a historicidade, e, portanto, a singularidade, das dinâmicas econômicas, modernas ou tradicionais.

Nas mesmas páginas, entretanto, Marx (2011) pontua o que seria uma maneira razoável de vocalizar a ideia de "produção em geral" (ainda que a partir da própria economia política clássica).

Diz ele que

[...] todas as épocas da produção têm certas características em comum, determinações em comum. A produção em geral é uma abstração, mas uma abstração razoável, na medida em que efetivamente destaca e fixa o elemento comum, poupando-nos assim da repetição. Entretanto, esse Universal, ou o comum isolado por comparação, é ele próprio algo multiplamente articulado, cindido em diferentes determinações. Algumas determinações pertencem a todas as épocas; outras são comuns apenas a algumas. [Certas] determinações serão comuns à época mais moderna e à mais antiga. Nenhuma produção seria concebível sem elas; todavia, se as línguas mais desenvolvidas têm leis e determinações em comum com as menos desenvolvidas, a diferença desse universal e comum é precisamente o que constitui seu desenvolvimento. As determinações que valem para a produção em geral têm de ser corretamente isoladas de maneira que, além da unidade - decorrente do fato de que o sujeito, a humanidade, e o objeto, a natureza, são os mesmos -, não seja esquecida a diferença essencial (MARX, 2011, p. 56-57).

Ou seja, a determinação da "produção em geral" é correta apenas na medida em que efetivamente permite demarcar tanto os elementos partilhados (mas, historicamente situados), quanto às características únicas dos vários arranjos produtivos, passados e presentes. Daí que um dado da razoabilidade das abstrações seja, justamente, a sua capacidade para informar as categorias, explicitando a unidade contraditória que elas exprimem, bem como a sua diferença específica, que lhes confere concreção.

Outro ponto diz respeito ao caráter histórico e efetivo das abstrações, inclusive em termos de validade e sucessão temporal. Em sua conhecida, e bastante revisitada, elaboração sobre o processo de trabalho, desenvolvida no Livro I d'O capital, Marx (2013) afirma que

\footnotetext{
O trabalho é, antes de tudo, um processo entre o homem e a natureza, processo este em que o homem, por sua própria ação, medeia, regula e controla seu metabolismo com a natureza. Ele se confronta com a matéria natural como com uma potência natural [Naturmacht]. A fim de se apropriar da matéria natural de uma forma útil para sua própria vida, ele põe em movimento as forças naturais pertencentes a sua corporeidade: seus braços e pernas, cabeça e mãos. Agindo sobre a natureza externa e modificando-a por meio desse movimento, ele modifica, ao mesmo tempo, sua própria natureza. Ele desenvolve as potências que nela jazem latentes e submete o jogo de suas forças a seu próprio domínio (MARX, 2013, p. 255).
}

O processo de trabalho aparece aqui como pressuposto concreto, fenômeno real de existência independente do investigador. Neste trecho Marx (2013) o apresenta como destituído de particularizações: qualquer trabalho é o metabolismo entre o homem e a natureza, determinação elementar da produção, que garante as condições para a vida humana em qualquer de suas formas sociais. 
Entretanto, como anota Paço Cunha (2012), Marx dirá que esta universalidade só pôde ser intelectivamente alcançada quando se apresentou na própria realidade objetiva. Foi possível caracterizar o labor a partir de determinações universais, porque a mais avançada das sociedades, em virtude do processo de valorização do capital, o engendra efetivamente como uma realidade indistinta, desprendida de suas determinabilidades.

Isto é,

[...] trabalho simplesmente, nem trabalho manufatureiro, nem comercial, nem agrícola, mas tanto um como os outros. Com a universalidade abstrata da atividade criadora de riqueza, tem-se agora igualmente a universalidade do objeto determinado como riqueza, o produto em geral, ou ainda o trabalho em geral, mas como trabalho passado, objetivado. [...] Poderia parecer que, com isso, apenas fora descoberta a expressão abstrata para a relação mais simples e mais antiga em que os seres humanos - seja qual for a forma de sociedade - aparecem como produtores. Por um lado, isso é correto. Por outro não. [...] A indiferença em relação ao trabalho determinado corresponde a uma forma de sociedade em que os indivíduos passam com facilidade de um trabalho a outro, e em que o tipo determinado do trabalho é para eles contingente e, por conseguinte, indiferente. Nesse caso, o trabalho deveio, não somente enquanto categoria, mas na efetividade [...] (MARX, 2011, 82-83).

As categorias e as abstrações que as fundamentam, portanto, tem sua validade posta pela efetividade da vida social, realidade esta em devir constante e com caráter de complexo. Temos aqui não apenas a explicitação de que o movimento do real esclarece a anterioridade dos conceitos, mas também uma explanação que expõe a importância decisiva da determinação social do pensamento para a compreensão dos problemas humanos. Ou seja, não apenas não existe neutralidade na interpelação dos fenômenos sociais, mas as próprias descobertas nesse âmbito dependem do desenvolvimento, da complexificação da sociabilidade, responsável por desafiar os sujeitos, cobrando a elucidação até mesmo dos traços mais simples e universais da realidade histórica.

Ou como diz Paço Cunha (2012):

As categorias são reproduções do efetivamente existente no pensamento. A sociedade capitalista em pauta é dada tanto na realidade quanto na cabeça e, assim, as categorias não são enxertadas subjetivamente, categorias subjetivas com as quais se ordena o efetivamente existente, mas 'expressam formas de ser, determinações da existência'. Tais categorias são originadas na própria materialidade das relações contidas nas formas de produção de determinadas sociedades, em que tais sociedades são uma produção particular e suas correspondentes relações (PAÇO CUNHA, 2012, p. 182).

Toda esta caracterização é aqui fundamental, uma vez que aponta para o desafio de uma elaboração marxista das profissões. Se é disto que se trata, não valem predefinições ou análises superficiais, aprisionadas na mera descrição dos fatos. A compreensão profunda do fenômeno profissional requer o seu tratamento objetivo, situado no âmbito da produção e reprodução das relações sociais. 


\title{
temporollis masmens wososworom
}

Analisar as profissões, portanto, é compreender a sua particularidade enquanto manifestação histórica concreta, isto é, como a afirmação e manutenção dos diversos tipos de especialização laborativa, com suas funções políticas e econômicas, colocadas por cada uma de suas trajetórias e características singulares. É também identificar as determinações constitutivas do fenômeno para além dos casos específicos, vendo-o como processo de complexificação dos sistemas laborais, como elemento da divisão do trabalho no capitalismo moderno. Ou seja, trata-se de apreender a conexão profunda entre o profissionalismo e as dinâmicas decisivas da totalidade social.

\section{OS CONTRIBUTOS DO SERVIÇO SOCIAL}

Supõe-se que no caminho para elaboração de um pensamento marxista sobre as profissões o Serviço Social Brasileiro possui contribuições relevantes a serem depuradas, oriundas de seus três nomes mais significativos.

Essa afirmação, todavia, não pode ser tratada de forma pacífica, uma vez que não se pode falar na existência de uma abordagem sistemática sobre sobre as ocupações no pensamento de Faleiros, lamamoto ou Netto. Como já apontado em Martins (2014b) esta condição reproduz a própria diferença metodológica entre o marxismo e a sociologia das profissões (em algumas oportunidades, inclusive, declarada ${ }^{3}$ ). Ou seja, prismar o fenômeno profissional a partir destes autores não significa buscar respostas prontas e diretas, mas pistas capazes de enriquecer a avaliação do problema.

O primeiro ponto a notar são possíveis conexões entre os dois campos. Faleiros (1997; 2011; 2013) mostra-se aqui de forma singular, sobretudo em obras como Estratégias em Serviço Social; Globalização, correlação de forças e Serviço Social, e; com destaque, Saber profissional e poder institucional (que reúne os excertos mais significativos para análise ora empreendida). Em seu pensamento a ideia de profissão surge ligada a discussão das instituições no âmbito das ciências sociais (feita a partir de teóricos como Madel T. Luz, Foucault, Bourdieu, entre outros).

Segundo ele:

\begin{abstract}
As instituições não são um simples fenômeno superestrutural. São organizações transversais a toda sociedade. Elas aparecem como mecanismos reguladores das crises do desenvolvimento capitalistas em todos os níveis. Mesmo distantes de uma empresa, elas podem 'compensar' desequilíbrios do processo produtivo. No interior de uma empresa produtiva, a institucionalização dos serviços sociais está vinculada ao processo político global do desenvolvimento das condições da acumulação do capital (FALEIROS, 1997, p. 32).
\end{abstract}

Instituições, portanto, seriam aparelhos de poder voltados regulação da atividade coletiva, na esfera da produção e principalmente da reprodução social. O processo de institucionalização corresponderia, em termos instrumentais, a um aprofundamento da racionalização típica dos mecanismos de controle social capitalistas. Nesse sentido, para Faleiros (1997), o avanço das instituições é o meio central da burocratização (com suas demandas de eficiência e legitimidade).

\footnotetext{
3 Iamamoto e Carvalho (1983) dizem, por exemplo, que sua análise "[...] não encontra suporte na bibliografia especializada [tradicional] do serviço social e da sociologia das profissões" (IAMAMOTO; CARVALHO, 1983, p. 18).
} 


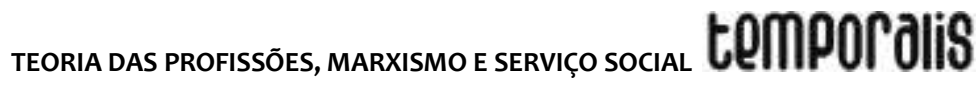

Ser profissional, em tal concepção, é estar inscrito nessa rede de correlações de força, enquanto agente que representa e participa de uma estrutura formal, ou seja, é ter suas ações e autoridade fundamentadas na dominação institucional, movimento que sempre repercute a dinâmica da sociedade em sentido amplo.

\begin{abstract}
As instituições na sua função de controle social, realizam formas de recuperação e de distensão social por intermédio da divisão dos clientes e dos problemas, do adiamento das soluções, do oferecimento de respostas simbólicas e parciais.

As pressões sociais são transformadas pela ordem institucional num problema específico, que deve ser tramitado hierarquicamente (de chefe em chefe), num determinado prazo de tempo e de acordo com a disciplina instituída (FALEIROS, 1997, p. 35).
\end{abstract}

Faleiros (1977), assim, ressalta (ao criticar as práticas do Serviço Social Tradicional) a figura do virtuose burocrático, o profissional para quem os objetivos institucionais tornam-se lógica, guia último de ação em contraponto às demandas postas pela sociedade. Não por caso, num texto intitulado Instituições de desenvolvimento e trabalho profissional ${ }^{4}$, ele faz menção a sociologia das profissões, num primeiro momento a Parsons e depois, com maior peso, a T. J. Johnson, teórico próximo a Freidson, para quem uma profissão não é uma ocupação, mas um meio de controle de uma ocupação, que gera uma situação de dependência da sociedade de grupos particulares, ampliando as clivagens e disputas sociais.

A incorporação dessas referências (com sua positividade e limitações) é consequência do próprio diálogo que Faleiros (2009; 2013) estabelece com o debate contemporâneo das ciências sociais (IAMAMOTO, 2008). Apesar da falta de sistematicidade (boa parte das citações são realizadas na forma de notas), nele a problemática das profissões não é absorvida de maneira passiva. Em Faleiros (1997) fica nítido que a profissionalização somente possui inteligibilidade à luz de dinâmicas econômico-sociais mais extensas, primeiro ao nível das instituições (com seus processos de controle social) e posteriormente, e de forma decisiva, na esfera da produção, que subscreve todo o funcionamento do corpo coletivo.

A contribuição a ser extraída de Faleiros (1997; 2009; 2013), portanto, caminha no sentido de mostrar que as descobertas da sociologia das profissões não podem ser aprisionadas num nível descritivo ou normativo (as profissões segundo a ideia que elas fazem de si mesmas, ou das expectativas que os teóricos dela possam ter), mas precisam ser tratadas a partir da realidade contraditória da qual fazem parte.

Não temos nesse caso uma plena ruptura com profissionalismo, mas uma forma de elaborar algumas de suas assertivas a partir de outra fundamentação. O rompimento decisivo ocorre, de fato, em lamamoto e Netto, cujas perspectivas oferecem caminhos amplamente convergentes no que toca ao estudo das ocupações especializadas.

lamamoto (2008), nesse caso, desenvolve seu pensamento negando toda forma de esquematismo para enquadrar o Serviço Social. O olhar exógeno a categoria é questão

\footnotetext{
${ }^{4}$ E que compõe o livro Saber profissional e poder institucional.
} 
central em sua análise, uma vez que o desenvolvimento dessa ocupação não tem razão em si. São as forças sociais que explicam o surgimento e evolução da profissão, não as suas características aparentes (deontologia, conteúdos formativos, atividades, reserva de mercado, etc.). Por esta ótica, como qualquer ocupação, o Serviço Social só pode ser explicado pela sociabilidade que o engendra, isto é, pelo modo de produção capitalista.

Nesses termos, e num nível de abstração mais amplo, temos que

\begin{abstract}
A divisão do trabalho na sociedade determina a vinculação dos indivíduos em órbitas profissionais específicas, tão logo o trabalho assume um caráter social, executado na sociedade e através dela. Com o desenvolvimento das forças produtivas sociais do trabalho, sob a égide do capital, o processo de trabalho passa a ser efetuado sob a forma de cooperação de muitos trabalhadores livres e máquinas no interior da fábrica. Verifica-se, ao mesmo tempo, um parcelamento das atividades necessárias à realização de um produto, sem precedentes em épocas anteriores, agora executados por diversos trabalhadores diferentes e por um sistema de máquinas. Cria-se o trabalhador parcial, efetuando-se o parcelamento do próprio indivíduo no ato da produção (IAMAMOTO; CARVALHO, 1983, p. 16-17).
\end{abstract}

Daí que a densificação da organização laboral surge como a base para a diversificação das ocupações, tornando necessária a subdivisão dos trabalhos e, de igual forma, a sua articulação com a totalidade da produção econômica. A partir de um extenso leque de mediações e particularizações essa dinâmica impactaria as mais variadas atividades, no campo industrial, comercial e no setor de serviços, originando novas categorias profissionais ou atualizando a conformação de especializações tradicionais, a exemplo da Medicina e do Direito. A autonomia relativa, a formação universitária, remuneração diferenciada e o status jurídico das ocupações profissionais se estabelecem nessa conjuntura como uma demanda do processo de trabalho e uma conquista (sempre incompleta) dos agentes de tais instituições.

Isto, é

O grau de desenvolvimento da divisão social do trabalho expressa o grau de desenvolvimento das forças produtivas sociais do trabalho. Com a divisão do trabalho dá-se, ao mesmo tempo, a distribuição quantitativa e qualitativa do próprio trabalho e dos seus produtos, isto é, da propriedade - do poder de dispor do trabalho de outros (IAMAMOTO; CARVALHO, 1983, p. 17).

Noutros termos mais precisos: as profissões são uma determinação da divisão social e técnica do trabalho modernas, elas exprimem a complexificação do labor e das instituições que lhes dão suporte. São, por isso, estruturas de poder econômico, político e cultural, não apenas porque mobilizam forças que interferem na identidade e nos valores dos sujeitos, ou porque provocam "coesão social”, mas sim por que estão inseridas (de maneira direta ou indireta) no circuito da mercantilização e do valor.

Por conseguinte, elas participam dos complexos que engendram as lutas de classe num duplo sentido: primeiro porque lidam com interesses e demandas contraditórias, oriundas de grupos com posições diferentes ou antitéticas no quadro coletivo, segundo: porque os agentes das profissões têm, eles próprios, um lugar de classe, isto é, compõe, em geral, a chamada pequena burguesia, com toda sua diversidade de frações e sujeitos. 
De forma semelhante pode-se observar em Netto (2007) apontamentos úteis para a avaliação das profissões, sobretudo em uma obra específica, Capitalismo Monopolista e Serviço Social. É nela que encontramos a assertiva segundo a qual o nascimento de uma profissão é sustentado por uma demanda social (lastreada em determinantes macroscópicos) capaz de ser instrumentalizada por um coletivo de trabalhadores. 0 estabelecimento de um corpo profissional se baseia, assim, na sua capacidade de elaborar respostas concretas a essas requisições, o que comporta, inclusive, o seu sentido sociopolítico mais amplo (ou seja, as demandas ocupacionais cumprem um papel no jogo responsável pela reprodução de uma sociedade).

Nesta ótica, claramente processual, as profissões precisam ser vistas como estruturas em constante mudança, dado o

[...] dinamismo histórico-social, que recoloca, a cada uma de suas inflexões a urgência de renovar (e, nalguns casos, de refundar) os estatutos das profissões particulares. Isto significa, que, em lapsos diacrônicos variáveis, todos os papéis profissionais veem-se em xeque - pelo nível de desenvolvimento das forças produtivas, pelo grau de agudeza e de explicitação das lutas de classe, pela emergência (ou rearranjo) de novos padrões jurídico-políticos etc. Decorrentemente a original legitimação de um estatuto profissional encontra-se periodicamente questionada - e não lhe é suficiente o apelo à sua fundamentação anterior, senão que se the põe como premente reatualização que a compatibilize com as demandas que se lhe apresentam (NETTO, 2007, p. 89).

Esta reconfiguração dinâmica é obviamente mediada pelos acúmulos das estruturas e agentes profissionais, que reagem ativamente às interpelações da conjuntura histórica, seja para se fortalecer ou se fragilizar diante de novos padrões tecnológicos, relações com o Estado, clientela, instituições empregadoras e outras ocupações.

Ou seja,

[...] a afirmação e o desenvolvimento de um estatuto profissional (e dos papéis a eles vinculados) se opera mediante a intercorrência de um duplo dinamismo: de uma parte, aquele que é deflagrado pelas demandas que the são socialmente colocadas; de outra, aquele que é viabilizado pelas suas reservas próprias de forças (teóricas e prático-sociais), aptas ou não para responder às requisições extrínsecas - e este é, enfim, o campo em que incide o seu 'sistema de saber' (NETTO, 2007, p. 92).

Do debate do Serviço Social temos, assim, que o mercado de trabalho, com suas demandas e oportunidades, é a força que funda uma prática profissional. Conhecimentos, proteção jurídica, metodologias, instrumentos e técnicas, não cria a profissionalidade de qualquer ofício, apenas a expressa e atualiza.

Geneticamente, as profissões vêm à luz quando o cenário social abre lugar para sua institucionalidade, tornando-a possível e necessária (NETTO, 2007). Tais coletivos estão sempre em desenvolvimento, mudando a partir das requisições extrínsecas da ordem social. As profissões e os profissionais participam da reprodução das classes e da luta de classes, possuindo um papel sociopolítico erigido a partir de seu lugar na estrutura coletiva (IAMAMOTO, 2008). Elas também se conformam e estão inseridas numa rede de relações de força, competindo com outras ocupações e instituições por poder, conhecimento e recursos (FALEIROS, 1997; 2009; 2013). 
Com isso, analisar o estabelecimento, as mudanças e a reprodução de um grupo ocupacional é traçar os fatos, estruturas e relações que o sustentam. Tal resolução é, essencialmente metodológica, contrastando com a sociologia das profissões, dado que reconhece a prática social como elemento central para o escopo e desenvolvimento da teorização.

\section{CONSIDERAÇÕES FINAIS}

Realizada a exposição é possível indicar (ainda que parcialmente) alguns elementos categoriais para uma discussão marxista das ocupações, recolhidos por meio do debate sobre o Serviço Social Brasileiro efetivado por Faleiros (1997; 2009; 2013), Iamamoto (2008) e Netto (2007).

Concretamente as profissões modernas são determinações da divisão social e técnica do trabalho burguesas, expressando o desenvolvimento e complexificação dos trabalhos e das demandas laborais, no âmbito da valorização do capital, da circulação de mercadorias e serviços, ou da burocracia estatal. A profissionalização é um processo dinâmico de densificação das estruturas de trabalho, por meio de suportes institucionais, que as tornam um complexo de poder, marcado por clivagens econômicas e culturais.

Exatamente por isso os coletivos profissionais integram a luta de classes, seja porque seus atores, usualmente, estão posicionados no seio dos extratos sociais médios, seja porque atendem a demandas direcionadas a sujeitos com necessidades contraditórias. Os sistemas de saber, técnicas e os discursos profissionais expressam esse quadro, são elementos fundamentais, mas não possuem prioridade determinativa no esclarecimento do estatuto das ocupações.

Tem-se por esta via, teórica e metodologicamente, o esboço de uma alternativa para o estudo do profissionalismo que, assim como a análise contemporânea do Serviço Social, busca inserir o problema no contexto da produção e reprodução das relações sociais.

\section{REFERÊNCIAS}

ALMEIDA, A. J. Contributos da sociologia para a compreensão dos processos de profissionalização. Medi@ções, Setúbal, v. 1, n. 2, p. 115-127, 2010. Disponível em: http://mediacoes.ese.ips.pt/index.php/mediacoesonline/article/viewFile/28/pdf_13. Acesso em: 1 fev. 2018.

APPLE, M. W. Trabalho docente e textos: economia política das relações de classe e gênero em educação. Porto Alegre: Artes Médica, 1995.

ASSUNÇÃO, V. N. F. de. A teoria das abstrações de Marx: o método científico exato para o estudo do ser social. Verinotio - revista online de filosofia e ciências humanas, n. 18, p. 4661, 2013. Disponível em: http://www.verinotio.org/conteudo/0.8857190030494.pdf. Acesso em: $21 \mathrm{fev} .2018$.

BRAVERMAN, H. Trabalho e capital monopolista: a degradação do trabalho no século XX. 3 . ed. Rio de Janeiro: LTC, 1987. 
CARVALHO, A. B. de. Magistratura e direito alternativo. São Paulo: Acadêmica, 1992.

CHASIN, J. Marx: estatuto ontológico e resolução metodológica. In: TEIXEIRA, F.

Pensando com Marx. São Paulo: Ensaio, 1995.

CORRIGAN, P; LEONARD, P. Social Work under captalism: a marxist approach. Londres: Macmillan, 1978.

DUBAR, C. A construção de si pela atividade de trabalho: a socialização profissional. Cad.

Pesqui., São Paulo, v. 42, n. 146, ago. 2012. Disponível em:

http://www.scielo.br/scielo.php?script=sci_arttext\&pid=S0100-

$15742012000200003 \&$ lng=pt\&nrm=iso. Acesso em: 1 fev. 2018.

DURAND, J. C. G. A serviço da coletividade: crítica à sociologia das profissões. Rev. adm. empres. [online]. 1975, vol.15, n.6, p.59-69. Disponível em:

http://www.scielo.br/scielo.php?script=sci_arttext\&pid=So034-

$75901975000600005 \&$ Ing=pt\&nrm=iso. Acesso em: 19 fev. 2018.

DURKHEIM, É. Da divisão do trabalho social. 2. ed. São Paulo: Martins Fontes, 2007.

EDGELL. S. Class. Londres: Routledge, 1993.

FALEIROS, V. de P. Metodologia e ideologia do trabalho social. 11.ed. São Paulo: Cortez, 2009.

FALEIROS, V. de P. Saber profissional e poder institucional. 5. ed. São Paulo: Cortez, 1997.

FALEIROS, V. de P. Estratégias em Serviço Social. 10. ed. São Paulo: Cortez, 2011.

FALEIROS, V. de P. Globalização, correlação de forças e Serviço Social. São Paulo: Cortez, 2013.

FERGUSON, I. Um outro Serviço Social é possível: reivindicando a tradição radical. Em Pauta, Rio de Janeiro: revista da Faculdade de Serviço Social da Universidade do Estado do Rio de Janeiro, n. 27, jul. 2011.

FREIDSON, E. Para uma análise comparada das profissões: a institucionalização do discurso e do conhecimento formais. Revista Brasileira de Ciências Sociais, São Paulo, v. 11, n. 31, p. 141-55, 1996.

FREIDSON, E. “A teoria das profissões: situação do setor”. In: FREIDSON, E. O renascimento do profissionalismo: teoria, profecia e política. São Paulo: Edusp, 1998, p. 47-63.

HUGHES, E. C. Men and their work. Londres: The Free Press of Glencoe-Collier Macmillan, 1958. 
IAMAMOTO, M. V. O Serviço Social em tempo de capital fetiche: capital financeiro, trabalho e questão social. 3. ed. São Paulo: Cortez, 2008.

IAMAMOTO, M. V.; CARVALHO, R. de. Relações sociais e Serviço Social no Brasil: esboço de uma interpretação histórico-metodológica. 2. ed. São Paulo: Cortez, 1983.

MARX, K. Grundrisse - manuscritos econômicos 1857-1858: esboços da crítica da economia política. São Paulo: Boitempo, 2011.

MARX, K. O capital: crítica da economia política. Livro I: o processo de produção do capital. São Paulo: Boitempo, 2013.

MARX, K.; ENGELS, F. A ideologia alemã: crítica da mais recente filosofia alemã em seus representantes Feuerbach, B. Bauer e Stirner, e do socialismo alemão em seus diferentes profetas - 1845-1846. São Paulo: Boitempo, 2007.

MARTINS, L. R. Crítica da legitimidade na teoria das profissões e suas contribuições para o debate sobre os fundamentos do Serviço Social. 2014. Dissertação (Mestrado) Universidade Federal de Juiz de Fora, Juiz de Fora, 2014a.

MARTINS, L. R. Teoria das profissões e a análise dos fundamentos do Serviço Social. Verinotio, revista on-line de Filosofia e Ciências Humanas, n. 20, p. 64-81, out. 2014b. Disponível em: http://www.verinotio.org/conteudo/0.46616944434696.pdf. Acesso em: 10 fev. 2018.

MENEGHETTI, G. Profissões e identidades profissionais: um estudo sobre as teorias e conceitos nas ciências sociais e no serviço social. 2009. Dissertação (Mestrado) Universidade Federal de Santa Catarina, Florianópolis, 2009.

MERTON, R. Social research and practicing professions. Nova lorque: University Press of America, 1982.

MERTON, R. Estrutura social e anomie. In: MERTON, R. Sociologia: teoria e estrutura. São Paulo: Mestre Jou, 1970. p. 203-234.

MONTAÑO, C. A natureza do Serviço Social: um ensaio sobre sua gênese, a "especificidade" e sua reprodução. 2.ed. São Paulo: Cortez, 2011.

NAVARRO, V. Medicine under capitalism. New York, Prodist, 1976.

NETTO, J. P. Capitalismo monopolista e Serviço Social. 6. ed. São Paulo: Cortez, 2007.

OPPENHEIMER, M. The proletarianization of the professional. The Sociological Review, v. 20, p. 2013-227, 1972.

PAÇO CUNHA, E. Rearticulação categorial ao pensamento marxiano: produção em geral, trabalho abstrato e burocracia. CSOnline (UFJF), v. 1, p. 175-201, 2012. Disponível em: https://csonline.ufjf.emnuvens.com.br/csonline/article/download/1739/1212. Acesso em: 19 fev. 2018. 
PARSONS, T. "Estructura social y proceso dinámico: el caso de la práctica médica moderna”. In: PARSONS, T. El sistema social. Madri: Alianza, 1982, p. 274-305.

PAYNE, M. Teoria do Trabalho Social Moderno. Coimbra: Quarteto, 2002.

SAVIANI, D. Escola e democracia: teorias da educação, curvatura da vara, onze teses sobre educação e política. 36. ed. São Paulo: Autores Associados; Cortez, 2003.

VERDÈS-LEROUX. J. Trabalhador social: prática, habitus, ethos, formas de intervenção. São Paulo: Cortez, 1986.

WRIGHT, E. O. Class Boundaries in Advanced Capitalist Societies. New Left Review, v. 98, p. 3-41, 1976.

\section{Ludson Rocha Martins}

Assistente social da Prefeitura Municipal de Nova Lima (PMNL) -, atuando na Política de Assistência Social (área de vigilância socioassistencial). Mestre em Serviço Social pela Universidade Federal de Juiz de Fora (UFJF). Investiga a temática dos fundamentos do Serviço Social, associada à questão da legitimidade no âmbito da teoria das profissões; possui, ainda, interesse no estudo dos problemas de gênero e da democracia. 